\section{$\underset{\substack{\text { hommes } \\ \text { \& migrations }}}{ }$}

\section{Hommes \& migrations}

Revue française de référence sur les dynamiques

migratoires

$1295 \mid 2012$

Algérie - France : une communauté de destin

\title{
Didier Daeninckx et Mako, Octobre noir
}

Préface de Benjamin Stora éditions Ad Libris, 2011, 60 pages, 13,50 euros

\section{Mustapha Harzoune}

\section{(2) OpenEdition}

1 Journals

\section{Édition électronique}

URL : http://journals.openedition.org/hommesmigrations/1098

DOI : 10.4000/hommesmigrations.1098

ISSN : 2262-3353

\section{Éditeur}

Musée national de l'histoire de l'immigration

\section{Édition imprimée}

Date de publication : 1 janvier 2012

Pagination : 181

ISSN : 1142-852X

\section{Référence électronique}

Mustapha Harzoune, «Didier Daeninckx et Mako, Octobre noir », Hommes \& migrations [En ligne], 1295।

2012, mis en ligne le 29 mai 2013, consulté le 22 septembre 2020. URL : http://

journals.openedition.org/hommesmigrations/1098; DOI : https://doi.org/10.4000/

hommesmigrations. 1098

Ce document a été généré automatiquement le 22 septembre 2020.

Tous droits réservés 


\title{
Didier Daeninckx et Mako, Octobre noir
}

Préface de Benjamin Stora éditions Ad Libris, 2011, 60 pages, 13,50 euros

\author{
Mustapha Harzoune
}

\section{RÉFÉRENCE}

Didier Daeninckx et Mako, Octobre noir, Préface de Benjamin Stora éditions Ad Libris, 2011, 60 pages, 13,50 euros

1 Début des années soixante. Blouson noir, banane, gomina and... rock \& roll tard, juste avant le dernier métro et le dernier petit trou pour le débonnaire poinçonneur de la station. Un autre temps... Il rentre chez lui, des rêves plein la tête. Dans deux jours, le 17 octobre 1961, avec ses potes, il doit participer à un tremplin de rock au Golf Drouot, à la clé : l'illustre scène de l'Olympia. La " concurrence" est rude : les Chaussettes noires d'un certain Eddy Mitchell et les Chats sauvages! Sur le chemin qui le conduit du côté de Saint-Denis, il est témoin d'un assassinat : deux flics en civil démolissent un Algérien avant de balancer le corps dans la Seine. Vincent court chez lui. Il habite, avec ses parents et sa sœur, une chambre d'hôtel.

2 Un hôtel pour immigrés algériens. Vincent s'appelle en fait Mohand. Dans la nouvelle "Des p'tits Ben Bella comme s'il en pleuvait", signée Akli Tadjer (17 octobre, 17 écrivains se souviennent, Au nom de la mémoire, 2011), un écolier cherche à éviter de participer à la manifestation des Algériens de Paris et de sa région décidée par le FLN et organisée le 17 octobre 1961. Le gamin souhaite réciter sa récitation à sa séduisante maîtresse. Justement ce 17 octobre ! Ce même jour, Mohand, alias Vincent, ne peut, lui, manquer le concert... Mais voilà, les injonctions du FLN sont sans appel et le nif exige ne de pas faire honte à ses parents : un dilemme.

3 À cette trame, la BD adapte un fait réel : la disparition d'une manifestante de 15 ans, Fatima Bédar, retrouvée morte quelques jours après la manifestation. Ici la gamine s'appelle Khelloudja, elle est la sœur de Mohand. Elle a désobéi à ses parents et elle est 
partie, en ce mardi pluvieux, manifester avec les autres Algériens de Paris. Mohand part à la recherche de sa sœur.

4 Le texte est signé Daeninckx et les planches, remarquables, de Mako (Lionel Makowski). Le décor est sombre et nocturne (Laurent Houssin est aux couleurs), le dessin est réaliste, vif et expressif, tour à tour menaçant, terrible, poignant.

5 En préface, l'historien Benjamin Stora fait le point sur les faits et les enjeux de cette manifestation. En postface, Didier Daeninckx donne un texte (publié dans le recueil 17 octobre, 17 écrivains se souviennent) sur la mort de la petite Fatima Bédar. Le livre se referme sur une liste, établie par Jean-Luc Einaudi, l'auteur de La Bataille de Paris (Seuil), la liste des "morts et disparus à Paris et dans la région parisienne" en septembre et octobre 1961. 